\title{
Commentary
}

\section{Stethoscope hygiene: A call to action. Recommendations to update the CDC guidelines}

\author{
Sarathi Kalra ${ }^{1}$, Alpesh Amin ${ }^{2}$, Nancy Albert ${ }^{3}$, Cindy Cadwell ${ }^{4}$, Cole Edmonson ${ }^{5}$, Robert Gaynes ${ }^{6}$, Mary Hand ${ }^{7}$, \\ Mark Marinella ${ }^{8}$, Colleen Morely ${ }^{9}$, Sandra Sieck ${ }^{10}$ and Rajiv S. Vasudevan ${ }^{11}$ \\ ${ }^{1}$ University of South Alabama, Mobile, Alabama, ${ }^{2}$ University of California-Irvine, Irvine, California, ${ }^{3}$ Nursing Institute, Cleveland Clinic Health System, Cleveland, \\ Ohio, ${ }^{4}$ Cadwell Consulting, Tacoma, Washington, ${ }^{5} \mathrm{AMN}$ Healthcare, San Diego, California, ${ }^{6}$ Emory University, Atlanta, Georgia, ${ }^{7}$ Retired-National Institutes of \\ Health, Bethesda, Maryland, ${ }^{8}$ Wright State University School of Medicine and Dayton Physicians Network, Dayton, Ohio, ${ }^{9}$ West Suburban Medical Center, Oak \\ Park, Illinois, ${ }^{10}$ Sieck Consulting, Mobile, Alabama and ${ }^{11}$ University of California-San Diego, San Diego, California
}

\begin{abstract}
Healthcare-acquired infections are a tremendous challenge to the US medical system. Stethoscopes touch many patients, but current guidance from the Centers for Disease Control and Prevention does not support disinfection between each patient. Stethoscopes are rarely disinfected between patients by healthcare providers. When cultured, even after disinfection, stethoscopes have high rates of pathogen contamination, identical to that of unwashed hands. The consequence of these practices may bode poorly in the coronavirus 2019 disease (COVID-19) pandemic. Alternatively, the CDC recommends the use of disposable stethoscopes. However, these instruments have poor acoustic properties, and misdiagnoses have been documented. They may also serve as pathogen vectors among staff sharing them. Disposable aseptic stethoscope diaphragm barriers can provide increased safety without sacrificing stethoscope function. We recommend that the CDC consider the research regarding stethoscope hygiene and effective solutions to contemporize this guidance and elevate stethoscope hygiene to that of the hands, by requiring stethoscope disinfection or change of disposable barrier between every patient encounter.
\end{abstract}

(Received 2 December 2020; accepted 5 March 2021; electronically published 19 May 2021)

The Centers for Disease Control and Prevention (CDC) reports that 72,000 hospital patients with healthcare-acquired infections (HAIs) died during their hospitalization in 2015. ${ }^{1}$ HAI mortality thus represents the equivalent of a jet airliner crashing, with zero survivors, every day in the United States. Although great effort has been undertaken to combat this tragedy by hand hygiene, the stethoscope, which drapes around necks, is placed in pockets, and is touched by unwashed hands day in and out, has predominately been ignored. The lack of attention to stethoscope hygiene belies contemporary data. Current Centers for Disease Control and Prevention (CDC) guidelines ${ }^{2}$ clearly state that "the stethoscope can be contaminated and spread disease." 3,4 Pathogens cultured from the medical practitioner's fingers are duplicated on the stethoscope diaphragm, ${ }^{5-7}$ which functions as a third hand ${ }^{8}$ in the spread of disease. Furthermore, the ability of the stethoscope to transmit bacteria from the diaphragm to the patient has also been documented. ${ }^{9-12}$ Despite data reflecting the need to disinfect it before use, stethoscope hygiene is essentially ignored in contemporary clinical practice. ${ }^{13-16}$

The CDC defines the stethoscope as a noncritical surface ${ }^{2}$ and states that weekly disinfection with alcohol is acceptable unless it is visibly soiled. Although this would never be acceptable for the

\section{Author for correspondence: Sarathi Kalra; Email sarathikalra@gmail.com}

Cite this article: Kalra S, et al. (2021). Stethoscope hygiene: A call to action. Recommendations to update the CDC guidelines. Infection Control \& Hospital Epidemiology, 42: 740-742, https://doi.org/10.1017/ice.2021.115 hands, the tool with identical pathogens and that is rubbed on the skin of a majority of patients is subject to vastly different disinfection recommendations than hands. The differences in the recommendations between the hands and the stethoscope should be addressed, especially now that the possibility of stethoscoperelated coronavirus disease 2019 (COVID-19) transmission must be considered. ${ }^{12,17}$ How many stethoscope transmissions may have occurred in the COVID-19 era?

The evidence suggests that isopropyl alcohol is partially effective in stethoscope disinfection. ${ }^{18}$ Recent studies show that disinfected stethoscopes can maintain significant rates of pathogen colonization. ${ }^{18-24}$ And after decades of alcohol disinfectant use, some pathogenic resistance to its sterilization effects have become apparent. ${ }^{25,26}$ Ultimately, although some pathogens are unaffected by alcohol (eg, Clostridioides difficile spores), ${ }^{27}$ the critical intervention to prevent their spread is the actual disinfection of the stethoscope. Unfortunately, no observational study, of the many that have been performed, has ever documented a reasonable rate of disinfection practice. ${ }^{8,13-15,28}$ Clearly, current CDC recommendations are inconsistent with the overwhelming number of publications demonstrating that self-disinfection by medical providers is ineffectual, ${ }^{15,20,29}$ inconsistent, ${ }^{30,31}$ and almost never practiced. ${ }^{13,14,32}$ In fact, when medical practitioners are asked, their self-reported stethoscope disinfecting rates commonly exceed $50 \%$; however, when cultured, the growth rate from stethoscopes reported to have been disinfected $>50 \%$ of the time is similar to that of observational stethoscope disinfection studies with

(c) The Author(s), 2021. Published by Cambridge University Press on behalf of The Society for Healthcare Epidemiology of America. This is an Open Access article, distributed under the terms of the Creative Commons Attribution licence (http://creativecommons.org/licenses/by/4.0/), which permits unrestricted re-use, distribution, and reproduction in any medium, provided the original work is properly cited. 
disinfection rates in the single digits. ${ }^{8,13-15,28}$ Clearly, self-reported hygiene rates are not a reliable metric.

Medical professionals generally understand the vector potential of the stethoscope. Although calls for regular stethoscope hygiene are not unusual, ${ }^{33}$ why are these disinfection practices universally ignored? It is the simple math of time. If a medical practitioner seeing 30 patients per day is expected to engage in a before-and-after stethoscope disinfection of 60 seconds, this equates to an hour per day dedicated to stethoscope disinfection. At this time cost, medical practitioner stethoscope hygiene between patients is not a viable strategy for promoting stethoscope hygiene. A more acceptable strategy could be disinfecting the stethoscope while introducing themselves or while having a discussion with the patient.

Alternatives to washing have been suggested. The most popular suggestion, and the one recommended by the $\mathrm{CDC}, 22$ is the disposable stethoscope. With this strategy, a patient receives an inexpensive stethoscope that every subsequent medical provider shares. This option is a tremendously undesirable solution for 2 reasons. First, medical providers are generally not interested in sharing what is likely a contaminated device among a group of practioners. Is there a more effective way of innoculating all your staff $^{34}$ than sharing the same undisinfected equipment? Second, disposable stethoscopes are lack quality and functionality. In a study of $>200$ auscultations, $10.9 \%$ of cardiac murmurs were simply misdiagnosed by physicians using the disposable stethoscope. In comparison, when high-quality stethoscopes with aseptic barriers were used, there was a $0 \%$ misdiagnosis rate..$^{35,36}$

Finally, the CDC recommends that if dedicated disposable devices are not available, the stethoscope should be disinfected after use on a patient who is on contact precautions before using this equipment on another patient. ${ }^{2}$ This implicit strategy of "the medical pratitioner should wash it" relies upon interventions, such as education, that have been uniquivocally proven to fail. ${ }^{16}$ Self-administered stethoscope hygiene has inherent human compliance challenges and logistical drawbacks that undermine its success to the point that it simply does not work.

Another common approach to preventing the spread of disease between patients is for the medical practitioner to wash their hands and then place a disposable glove over the stethoscope diaphragm. Although this solution is likely acoustically superior to the disposable stethoscope, handling the stethoscope diaphragm effectively shares contaminants between it and the medical pratcitioner's just-washed hands.

Clearly, hand washing saves lives. In fact, the World Health Organization advocates that effective hand hygiene is the single most important practice to prevent and control HAIs. ${ }^{37,38}$ Because pathogens on the hands are identical to the pathogens on the stethoscope, it follows that if removing pathogens from the hands by washing is an effective infection control intervention, then preventing the same bugs from being spread by the stethoscope could have similar beneficial effects.

Recently, disposable barriers to prevent the spread of pathogens have been evaluated and recommended ${ }^{30}$ because they allow highfidelity acoustic performance. ${ }^{35,36}$ Disposable barriers that can be applied via a touch-free dispsenser (thus preventing contamination with hand pathogens) have been documented to prevent the transmission of many HAI pathogens, including methicillin resistant Staphylococcus aureus, C. difficile, and vancomycin-resistant Enterococcus. ${ }^{39-41}$ Such barriers are acoustically invisible to the sound transmission of the stethoscope. Although data demonstrating that compliance with stethoscope barriers would be superior to that of standard cleaning/disinfection is unavailable, some have even recommended that barriers be impregnated with antibiotics or copper to inhibit bacterial growth. ${ }^{42}$ However, these latter solutions are probably inferior to the simple barrier becaudse they are likely to ultimately result in higher rates of bacterial resistance.

Ultimately, the "triple aim" ${ }^{\circ}$ of patient care includes quality, experience, and costs. Fewer HAIs would clearly contribute to higher quality, improved patient experience, and markedly lower costs. Use of an aseptic membrane as a barrier between the patient and a contaminated stethoscope diaphragm would contribute to all aspects of this triple aim. The logic of resistance to adopting disposable aseptic stethoscope diaphragm barriers as a standard of care is unclear given our current healthcare environment.

We are currently amid a COVID-19 pandemic, with the potential to amplify deficiencies in infection control. Our HAI prevention strategies need to reflect contemporary interventions that are universally easy to use. Since 2008, >20 publications have asserted the need to elevate the priority of stethoscope hygiene. During this period, innovation has brought highly effective aseptic barriers to market that have the potential to block pathogen transmission, improve provider compliance, and save clinician's time. We recommend that the CDC consider the research that has evolved in the area of stethoscope hygiene and effective solutions and contemporize its guidance to elevate stethoscope hygiene to that of hands. Stethoscope disinfection or the use of disposable barriers should be required between every patient encounter.

\section{Acknowledgments.}

Financial support. No financial support was provided relevant to this article.

Conflicts of interest. Sarathi Kalra reports a Clinical Trials research grant from Aseptiscope (the makers of a stethoscope cover). Alpesh Amin reports receiving funds from Clinical Trials PI/Co-I - NIH/NIAID, NeuroRx Pharma, Pulmotect, Blade Therapeutics, Novartis, Takeda, Humanigen, EliLliy, PTC Therpeutics, OctaPharma, Fulcrum Therapeutics, and Alexion as well as consultant fees and/or speaker fees from BMS, Pfizer, BI, Portola, Sunovion, Mylan, Alexion, Astra Zeneca, Novartis, Nabriva, Paratek, Bayer, Tetraphase, Achogen, LaJolla, Millenium, HeartRite, Sprightly. Alpesh Amin also reports consultant fees and stock options from Aseptiscope. Cindy Cadwell reports consulting fees from Aseptiscope. Sandra Sieck is an owner of Sieck Healthcare and reports consulting fees from AseptiScope, Dacor Corp, Osler Diagnostics, and Abbott Laboratories. All other authors report no conflicts of interest relevant to this article.

\section{References}

1. Healthcare-associated infections data portal. Centers for Disease Control and Prevention website. https://www.cdc.gov/hai/data/portal/index.html. Accessed January 27, 2020.

2. Rutala WA, Weber DJ, and the Healthcare Infection Control Practices Advisory Committee (HICPAC). Guideline for disinfection and sterilization in healthcare facilities, 2008. Centers for Disease Control and Prevention website. https://www.cdc.gov/infectioncontrol/pdf/guidelines/ disinfection-guidelines-H.pdf. Updated May 2019. Accessed March 22, 2021.

3. Guinto $\mathrm{CH}$, Bottone EJ, Raffalli JT, Montecalvo MA, Wormser GP. Evaluation of dedicated stethoscopes as a potential source of nosocomial pathogens. Am J Infect Control 2002;30:499-502.

4. Queiroz JRA, Melo IO, Santos Calado GH, Cavalcanti LRC, Sobrinho CRW. Identification and resistance profile of bacteria isolated on stethoscopes by healthcare professionals: systematic review. Am J Infect Control 2021;49: 229-237.

5. Longtin Y, Schneider A, Tschopp C, et al. Contamination of stethoscopes and physicians' hands after a physical examination. Mayo Clin Proc 2014;89:291-299.

6. Schneider A, Tschopp C, Longtin Y, et al. Predictors of stethoscope contamination following a standardized physical exam. BMC Proc 2011;5:304. 
7. Tschopp C, Schneider A, Longtin Y, Renzi G, Schrenzel J, Pittet D. Predictors of heavy stethoscope contamination following a physical examination. Infect Control Hosp Epidemiol 2016;37:673-679.

8. Jenkins IH, Monash B, Wu J, Amin A. The third hand: low rates of stethoscope hygiene on general medical services. J Hosp Med 2015;10: 457-458.

9. Marinella M, Pierson C, Chenoweth C. The stethoscope: a potential source of nosocomial infection? Arch Intern Med 1997;157:786-790.

10. Thakur M, Alhmidi H, Cadnum JL, et al. Use of viral DNA surrogate markers to study routes of transmission of healthcare-associated pathogens. Infect Control Hosp Epidemiol 2021;42:274-279.

11. Alhmidi H, Li DF, Cadnum JL, et al. Use of simulations to evaluate the effectiveness of barrier precautions to prevent patient-to-patient transfer of healthcare-associated pathogens. Infect Control Hosp Epidemiol 2020. doi: 10.1017/ice.2020.1215.

12. Vasudevan RS, Bin Thani K, Aljawder D, Maisel S, Maisel AS. The stethoscope: a potential vector for COVID-19? Eur Heart J 2020;41: 3393-3395.

13. Boulée D, Kalra S, Haddock A, Johnson TD, Peacock WF. Contemporary stethoscope cleaning practices: what we haven't learned in 150 years. Am J Infect Control 2019;47:238-242.

14. Vasudevan RS. Observation of stethoscope sanitation practices in an ED setting. Am J Infect Control 2019;47:234-237.

15. Alali SA, Shrestha E, Kansakar AR, Parekh A, Dadkhah S, Peacock WF. Community hospital stethoscope cleaning practices and contamination rates. Am J Infect Control 2020;48:1365-1369.

16. Holleck JL, Merchant N, Lin S, Gupta S. Can education influence stethoscope hygiene? Am J Infect Control 2017;45:811-812.

17. Pasquarella C, Colucci ME, Bizzarro A, et al. Detection of SARS-CoV-2 on hospital surfaces. Acta Biomed 2020; 91 suppl 9:76-78.

18. Parmar RC, Valvi CC, Sira P, et al. A prospective, randomised, double-blind study of comparative efficacy of immediate versus daily cleaning of stethoscope using 66\% ethyl alcohol. Indian J Med Sci 2004;58:423-430.

19. Russell A, Secrest J, Schreeder C. Stethoscopes as a source of hospitalacquired methicillin-resistant Staphylococcus aureus. J Perianesth Nurs 2012;27:82-87.

20. Zachary KC, Bayne PS, Morrison VJ, Ford DS, Silver LC, Hooper DC. Contamination of gowns, gloves, and stethoscopes with vancomycin-resistant enterococci. Infect Control Hosp Epidemiol 2001;22:560-564.

21. Favero MS, Bond WW. Chemical disinfection of medical and surgical materials. In: Block SS, ed. Disinfection, Sterilization, and Preservation. Philadelphia: Lippincott Williams \& Wilkins; 2001:881-917.

22. Whittington AM, Whitlow G, Hewson D, et al. Bacterial contamination of stethoscopes on the intensive care unit. Anaesthesia 2009;64: 620-624.

23. Alleyne SA, Hussain AM, Clokie M, Jenkins DR. Stethoscopes: potential vectors of Clostridium difficile. J Hosp Infect 2009;73:187-189.

24. Knecht VR, McGinniss JE, Shankar HM, et al. Molecular analysis of bacterial contamination on stethoscopes in an intensive care unit. Infect Control Hosp Epidemiol 2019;40:171-177.
25. Pidot SJ, Gao W, Buultjens AH, et al. Increasing tolerance of hospital Enterococcus faecium to handwash alcohols. Sci Transl Med 2018;10(452): eaar6115.

26. Wilcox MH, Fawley WN. Hospital disinfectants and spore formation by Clostridium difficile. Lancet 2000;356:1324.

27. Jabbar U, Leischner J, Kasper D, et al. Effectiveness of alcohol-based hand rubs for removal of Clostridium difficile spores from hands. Infect Control Hosp Epidemiol 2010;31:565-570.

28. Jones JS, Hoerle D, Riekse R. Stethoscopes: a potential vector of infection? Ann Emerg Med 1995;26:296-299.

29. Nunez S, Moreno A, Green K, Villar J. The stethoscope in the ED: a vector of infection? Epidemiol Infect 2000;124:233-237.

30. Smith, ML. Mathewson JJ, Ulert IA, Scerpell EG, Ericsson CD. Contaminated stethoscopes revisited. Arch Int Med 1996;156:82-84.

31. Muniz J, Sethi RKV, Zaghi J, Ziniel SI, Sandora TJ. Predictors of stethoscope disinfection among pediatric healthcare providers Am J Infect Control 2012;40:922-925.

32. Saunders C, Hryhorskyj L, Skinner J. Factors influencing stethoscope cleanliness among clinical medical students. J Hosp Infect 2013;84:242-244.

33. Lecat P, Cropp E, McCord G, Haller NA. Ethanol-based cleanser versus isopropyl alcohol to decontaminate stethoscopes. Am J Infect Control 2009;37:241-243.

34. Marinella M. COVID-19 pandemic and the stethoscope: do not forget to sanitize. Heart Lung 2020;49:350.

35. Kalra S, Garri RF, Shewale JB. Aseptic disposable stethoscope barrier: acoustically invisible and superior to disposable stethoscopes. Mayo Clin Proc. 2021;96:263-264.

36. Kalra S, Shewale JB, Peacock WF. Are stethoscopes and infection control enemies? Ann of EM. 2020;76:257.

37. Collins AS. Preventing health care-associated infections, chapter 41. In: Hughes RG, editor. Patient Safety and Quality: An Evidence-Based Handbook for Nurses. Rockville, MD: Agency for Healthcare Research and Quality; 2008.

38. Pittet D, Allegranzi B, Sax H, et al. WHO Global Patient Safety Challenge, World Alliance for Patient Safety. Evidence-based model for hand transmission during patient care and the role of improved practices. Lancet Infect Dis 2006;6:641-652.

39. Vasudevan R, Shin JH, Chopyk J, et al. Aseptic barriers allow a clean contact for contaminated stethoscope diaphragms. Mayo Clin Proc Innov Qual Outcomes 2020;4:21-30.

40. Vasudevan R. Kalra S. Torriani FJ, Peacock WF. Effectiveness of aseptic stethoscope barriers in allowing clean contact for Clostridioides difficilecontaminated stethoscopes. Abstract 907061 presented at: ID Week 2020; October 2020; conducted virtually.

41. Peacock WF, Kalra S, Vasudevan R. Aseptic stethoscope barriers prevent $C$. difficile transmission in vitro. Mayo Clin Proc Innov Qual Outcomes 2021;5:103-108.

42. Schmidt MG, Tuuri RE, Dharsee A, et al. Antimicrobial copper alloys decreased bacteria on stethoscope surfaces. Am J Infect Control 2017;45:642-647. 